\title{
Comparison of Cryotop and micro volume air cooling methods for cryopreservation of bovine matured oocytes and blastocysts
}

\author{
Kanchana PUNYAWAI 1, 2), Nitira ANAKKUL ${ }^{2,3)}$, Kanokwan SRIRATTANA ${ }^{1)}$, Yoshio AIKAWA ${ }^{2)}$, \\ Siwat SANGSRITAVONG ${ }^{4)}$, Takashi NAGAI ${ }^{5-7)}$, Kei IMAI ${ }^{2,8)}$ and Rangsun PARNPAI ${ }^{1)}$ \\ 1) Embryo Technology and Stem Cell Research Center and School of Biotechnology, Suranaree University of Technology, \\ Nakhon Ratchasima 30000, Thailand \\ 2) National Livestock Breeding Center, Fukushima 961-8511, Japan \\ 3) Department of Obstetric Gynecology and Reproduction, Faculty of Veterinary Science, Chulalongkorn University, \\ Bangkok 10330, Thailand \\ 4) National Center for Genetic Engineering and Biotechnology, National Science and Technology Development Agency, \\ Pathum Thani 12120, Thailand \\ 5) Food and Fertilizer Technology Center, Taipei 10648, Taiwan \\ ${ }^{6)}$ Department of Agricultural Biotechnology, College of Agriculture and Life Sciences, Seoul National University, Seoul 151- \\ 742, Republic of Korea \\ 7) Animal Breeding and Reproduction Research Division, NARO Institute of Livestock and Grassland Science, National \\ Agriculture and Food Research Organization (NARO), Ibaraki 305-0901, Japan \\ ${ }^{8)}$ Department of Sustainable Agriculture, Rakuno Gakuen University, Hokkaido 069-8501, Japan
}

\begin{abstract}
This study was designed to compare the efficiency of the Cryotop method and that of two methods that employ a micro volume air cooling (MVAC) device by analyzing the survival and development of bovine oocytes and blastocysts vitrified using each method. In experiment I, in vitro-matured (IVM) oocytes were vitrified using an MVAC device without direct contact with liquid nitrogen ( $\mathrm{LN}_{2}$; MVAC group) or directly plunged into $\mathrm{LN}_{2}\left(\mathrm{MVAC}\right.$ in $\mathrm{LN}_{2}$ group). A third group of IVM oocytes was vitrified using a Cryotop device (Cryotop group). After warming, vitrified oocytes were fertilized in vitro. There were no significant differences in cleavage and blastocyst formation rates among the three vitrified groups, with the rates ranging from $53.1 \%$ to $56.6 \%$ and $20.0 \%$ to $25.5 \%$, respectively; however, the rates were significantly lower $(\mathrm{P}<0.05)$ than those of the fresh control group $(89.3 \%$ and $43.3 \%$, respectively) and the solution control group $(87.3 \%$ and $42.0 \%$, respectively). In experiment II, in vitro-produced (IVP) expanded blastocysts were vitrified using the MVAC, MVAC in LN 2 and Cryotop methods, warmed and cultured for survival analysis and then compared with the solution control group. The rate of development of vitrified-warmed expanded blastocysts to the hatched blastocyst stage after 24 h of culture was lower in the MVAC in $\mathrm{LN}_{2}$ group than in the solution control group; however, after 48-72 h of culture, the rates did not significantly differ between the groups. These results indicate that the MVAC method without direct $\mathrm{LN}_{2}$ contact is as effective as the standard Cryotop method for vitrification of bovine IVM oocytes and IVP expanded blastocysts.
\end{abstract}

Key words: Blastocysts, Cryodevice, Cryotop, Micro volume air cooling, Oocytes

(J. Reprod. Dev. 61: 431-437, 2015)

$\mathbf{V}$ itrification was initially used for cryopreservation of mouse embryos [1], and it has become a viable alternative to traditional freezing protocols, as it prevents chilling injury and ice crystal formation. During the vitrification procedure, cells and tissues are exposed to a high concentration of cryoprotectants (CPAs), which effectively dehydrate the cells prior to initiation of the cooling process. Extended exposure to a high concentrations of permeating

Received: December 18, 2014

Accepted: May 29, 2015

Published online in J-STAGE: June 28, 2015

C 2015 by the Society for Reproduction and Development

Correspondence: K Imai (e-mail: imai@rakuno.ac.jp), R Parnpai (e-mail: rangsun@g.sut.ac.th)

This is an open-access article distributed under the terms of the Creative Commons Attribution Non-Commercial No Derivatives (by-nc-nd) License $<$ http://creativecommons.org/licenses/by-nc-nd/3.0/>.
CPAs is detrimental to cells [2]. To achieve a high probability of successful vitrification, the volume of the vitrification solution is minimized, which increases the cooling velocity and heat transfer and prevents ice crystal formation [3]. A rapid cooling rate during vitrification is the key to successful vitrification that avoids chilling injury in sensitive cells [4].

Oocytes are highly sensitive to chilling because of their low surface-to-volume ratio, which makes it difficult for water and CPAs to move across the cell plasma membranes [5]. Furthermore, vitrification of mature oocytes that are in metaphase of meiosis II (MII) leads to disorganization or disruption of the meiotic spindle, resulting in chromosome aberration $[6,7]$. The first successful vitrification of MII bovine oocytes was performed using electron microscope grids and a $0.25-\mathrm{ml}$ straw as a vitrification device [8]. Since then, other methods, such as the solid surface vitrification and Cryotop methods, have been found to allow for high-efficiency 
vitrification of MII bovine oocytes $[9,10]$. In contrast, embryos are more cryotolerant than oocytes because the properties of the plasma membrane change after fertilization, promoting dehydration and reducing ice formation during cryopreservation [11]. Massip et al. [12] were the first to report successful vitrification of bovine embryos using a $0.25-\mathrm{ml}$ straw. Since then, several vitrification devices have been developed, each with a specific method of minimizing the volume of the vitrification solution: the Cryoloop [13], nylon loop [14], hemi-straw system [15], electron microscopy grid [8], open pulled straw [16], glass capillary [17] and Cryotop [18].

The Cryotop method is one of the most efficient techniques for vitrification of both oocytes and embryos, resulting in high survival and developmental rates in pigs [19-21], cattle [8, 9, 22], buffalo [23-25] and humans [26, 27]. However, because it is an open method in which samples come into direct contact with $\mathrm{LN}_{2}$, it allows for the possibility of microbial disease transmission and viral contamination [28]. Therefore, a new device and the corresponding micro volume air cooling (MVAC) method have been invented to prevent direct contact with $\mathrm{LN}_{2}$ during vitrification. The MVAC and Cryotop devices are equally effective for vitrification of in vivo-derived porcine expanded blastocysts [29]. However, there have been no reports on application of the MVAC device (both with and without direct exposure to $\mathrm{LN}_{2}$ ) to oocytes and embryos at the blastocyst stage in bovine species.

The objective of this study was to compare the efficacy of the MVAC and Cryotop devices for vitrification of both bovine in vitro-matured (IVM) oocytes and bovine in vitro-produced (IVP) embryos at the blastocyst stage by analysis of subsequent in vitro development after warming.

\section{Materials and Methods}

\section{Chemicals and media}

All reagents were purchased from Sigma-Aldrich Corporation (St. Louis, MO, USA), unless otherwise indicated.

\section{Oocyte collection and IVM}

Collection and IVM of bovine follicular oocytes were performed as previously described [30]. Briefly, slaughterhouse ovaries were washed and stored in physiological saline supplemented with $50 \mu \mathrm{g} / \mathrm{ml}$ gentamicin for approximately $20 \mathrm{~h}$ at $20 \mathrm{C}$. Cumulus-oocyte complexes (COCs) were aspirated from follicles (2-8 $\mathrm{mm}$ in diameter) using a $5 \mathrm{ml}$ syringe connected to a 19-gauge needle. The IVM medium consisted of 25 mM Hepes-buffered TCM199 (Life Technologies Gibco-BRL Division, Grand Island, NY, USA) and 5\% calf serum (CS; Life Technologies Gibco-BRL Division). COCs were washed twice with IVM medium and then cultured for $20 \mathrm{~h}$ in $600-\mu 1$ droplets of IVM medium (80-100 oocytes/droplet) that were covered with paraffin oil (Nacalai Tesque, Kyoto, Japan) in 35-mm plastic dishes (Nalge Nunc International, Roskilde, Denmark) at 38.5 C under a humidified atmosphere of $5 \% \mathrm{CO}_{2}$ in air.

\section{Vitrification and warming of oocytes}

Twenty hours after IVM, cumulus cells were partially removed by repeated pipetting using a fine glass pipette in Dulbecco's phosphatebuffered saline (DPBS; Life Technologies Gibco-BRL Division) supplemented with $0.1 \%(\mathrm{w} / \mathrm{v})$ hyaluronidase. IVM oocytes with two to three layers of cumulus cells on their surface were subsequently washed five times in holding medium (HM), which consisted of 25 mM Hepes-buffered TCM 199 supplemented with 20\% (v/v) CS. Thereafter, they were vitrified using either the MVAC device or the Cryotop device (Kitazato BioPharma, Shizuoka, Japan) in a vitrification solution, as described previously by Dinnyes et al. [9]. Briefly, three separate groups of 5-10 oocytes were placed in equilibration medium, which was composed of HM supplemented with 4\% (v/v) ethylene glycol (EG; Wako Pure Chemical Industries, Osaka, Japan), for $12-15 \mathrm{~min}$ at $38.5 \mathrm{C}$ and then transferred into a vitrification solution composed of HM supplemented with $35 \%$ EG, $50 \mathrm{mg} / \mathrm{ml}$ polyvinyl pyrrolidone, and $0.4 \mathrm{M}$ trehalose. Then, one group of 5-10 oocytes (Cryotop group) was placed on a Cryotop sheet as described previously [10], while another group was placed in a small volume of vitrification solution $(<1 \mu l)$ on the inner surface of a stainless steel sheet in the MVAC device, which was then plunged directly into $\mathrm{LN}_{2}$ (MVAC in $\mathrm{LN}_{2}$ group). The third group was treated with the MVAC method (MVAC group), as follows: A $0.25-\mathrm{ml}$ plastic straw was precooled in $\mathrm{LN}_{2}$ while sealed with a plastic plug to prevent $\mathrm{LN}_{2}$ from entering the straw. Thereafter, the plug was removed, and the entire of the MVAC device containing oocytes was then inserted into the straw. The straw containing the MVAC device was then plunged into $\mathrm{LN}_{2}$ [29]. Each cryodevice containing oocytes was kept in $\mathrm{LN}_{2}$ for at least $24 \mathrm{~h}$.

While submerged in $\mathrm{LN}_{2}$, cover straws were removed from the vitrification devices used for the Cryotop and MVAC in $\mathrm{LN}_{2}$ groups, followed by removal of the devices from inner straws. For the MVAC group, the cover straw was removed from the device above the surface of the $\mathrm{LN}_{2}$, ensuring that the oocytes could be warmed without directly contacting $\mathrm{LN}_{2}$. Thereafter, the devices were transferred into $3 \mathrm{ml}$ of warming solution, which was composed of HM supplemented with $0.3 \mathrm{M}$ trehalose, in a $35-\mathrm{mm}$ plastic dish at $38.5 \mathrm{C}$. Two minutes later, oocytes were consecutively transferred to $500-\mu 1$ droplets of HM supplemented with $0.15,0.075$ or 0.0375 $\mathrm{M}$ trehalose at $38.5 \mathrm{C}$, where they were held for $1 \mathrm{~min}$ each. They were washed three times with $\mathrm{HM}$ at $38.5 \mathrm{C}$ and then transferred into IVM medium and incubated for an additional $2 \mathrm{~h}$ at $38.5 \mathrm{C}$ in a humidified atmosphere of $5 \% \mathrm{CO}_{2}$ in air.

\section{In vitro fertilization (IVF)}

The vitrified-warmed oocytes and non-vitrified oocytes were subjected to IVF as described previously [30]. Briefly, frozen semen from a Japanese Black bull was thawed in a $37 \mathrm{C}$ water bath for $30 \mathrm{sec}$ and then centrifuged in $3 \mathrm{ml}$ of $90 \%$ Percoll solution at 740 $\times g$ for $10 \mathrm{~min}$. The pellet was resuspended and centrifuged in 6 $\mathrm{ml}$ of BO medium [31] supplemented with $10 \mathrm{mM}$ hypotaurine (Novo-heparin Injection 1000; Aventis Pharma, Tokyo, Japan) and 4 $\mathrm{U} / \mathrm{ml}$ heparin (Novo-heparin Injection 1000; Aventis Pharma) at 540 $\times g$ for $5 \mathrm{~min}$. Then, the pellet was resuspended with BO medium supplemented with $20 \mathrm{mg} / \mathrm{ml} \mathrm{BSA} \mathrm{(IVF} \mathrm{medium)} \mathrm{to} \mathrm{reach} \mathrm{a} \mathrm{final}$ concentration of $3 \times 10^{6}$ spermatozoa $/ \mathrm{ml}$. To prepare fertilization droplets, $100-\mu 1$ droplets of the sperm suspension were placed in a $35-\mathrm{mm}$ dish and covered with paraffin oil. A group of 20 oocytes was washed three times in IVF medium. The oocytes were transferred into the fertilization droplets and cultured for $6 \mathrm{~h}$ at $38.5 \mathrm{C}$ under a 
humidified atmosphere of $5 \% \mathrm{CO}_{2}$ in air.

In vitro culture (IVC) of embryos

After IVF, cumulus cells and sperm attached to oocytes were removed by gentle pipetting with a fine glass pipette. IVC was performed in CR1aa medium [32] supplemented with 5\% CS and covered with paraffin oil in a $35-\mathrm{mm}$ dish at $38.5 \mathrm{C}$ under a humidified atmosphere of $5 \% \mathrm{CO}_{2}$ in air. Twenty presumptive zygotes derived from vitrified oocytes and fresh oocytes (Experiment I) were cultured in a $100-\mu 1$ IVC drop, and 80 presumptive zygotes derived from vitrified oocytes and fresh oocytes (Experiment II) were cultured in a 600- $\mu$ IVC drop. After culture for $48 \mathrm{~h}$, cleavage rates were recorded. The blastocysts were continuously cultured in the same drop without changing the medium. Blastocyst formation rates were recorded on days 7,8 , and 9 (day 0 was defined as the day of IVF).

\section{Vitrification of IVP expanded blastocysts}

Grade 1 IVP expanded blastocysts (IETS code $7 ; \mathrm{n}=345$ ) obtained on day 7 were vitrified using either the Cryotop or MVAC device. Briefly, the expanded blastocysts were washed three times in HM consisting of DPBS supplemented with $20 \%$ (v/v) CS. The expanded blastocysts were then placed in equilibration medium, which was composed of HM supplemented with 7.5\% EG and 7.5\% dimethyl sulfoxide (DMSO) for $3 \mathrm{~min}$ at $38.5 \mathrm{C}$, and then transferred into a vitrification solution composed of HM supplemented with $16.5 \%$ EG, $16.5 \%$ DMSO and $0.5 \mathrm{M}$ sucrose (VS33 solution), where they were held for $1 \mathrm{~min}$. Then, a group of three to five blastocysts was placed either on the inner surface of an MVAC device [29] or on a Cryotop device before vitrification by the MVAC, MVAC in $\mathrm{LN}_{2}$, or Cryotop method. Thereafter, cryodevices containing IVP expanded blastocysts were immediately plunged into $\mathrm{LN}_{2}$, where they were stored for at least $24 \mathrm{~h}$.

\section{Culture of vitrified-warmed IVP expanded blastocysts}

In each vitrification method, cover straws were removed from the devices in a process similar to the cover straw removal process used during vitrification and warming of oocytes, which was described above. After being washed in HM three times, the devices were placed in TCM-199 (Life Technologies Gibco-BRL Division) supplemented with $20 \% \mathrm{CS}$ and $0.1 \mathrm{mM} \beta$-mercaptoethanol, and then cultured for 72 $\mathrm{h}$ in the same medium (3-4 blastocysts $/ 20 \mu \mathrm{l}$ ) covered with paraffin oil at $38.5 \mathrm{C}$ in a humidified atmosphere of $5 \% \mathrm{CO}_{2}$ in air. To evaluate blastocyst survival after vitrification-warming, the percentages of vitrified-warmed expanded blastocysts that developed to the hatched blastocyst stage were determined at 24,48 , and $72 \mathrm{~h}$ of IVC.

\section{Evaluation of blastocyst cell numbers with differential staining}

Differential staining of inner cell mass (ICM) and trophectoderm (TE) nuclei in blastocysts was performed as previously described [33], with slight modifications. Briefly, the blastocysts were simultaneously treated with $0.1 \mathrm{mg} / \mathrm{ml}$ propidium iodide (PI) and $0.2 \%$ Triton X-100 dissolved in DPBS for $60 \mathrm{sec}$ to permeabilize the membrane and stain the nuclei of TE cells. The blastocysts were then treated for 5 min with $25 \mu \mathrm{g} / \mathrm{ml}$ Hoechst 33342 (Calbiochem, San Diego, CA, USA) dissolved in $99.5 \%$ ethanol, and then mounted on glass slides in glycerol droplets that were flattened by cover slips. The blastocysts were examined under UV light with an excitation wavelength of 330-385 nm using an epifluorescence microscope (IX-71; Olympus, Tokyo, Japan). The nuclei of TE cells labeled with both PI and Hoechst 33342 appeared pink or red, whereas the nuclei of ICM cells labeled only with Hoechst 33342 appeared blue. A digital image of each blastocyst was captured, and the cell numbers of both cell types were counted using the NIH ImageJ (v. 1.40) software [34]. Numbers of ICM and TE cells were counted separately in blastocysts that had clearly distinguishable populations of red and blue nuclei.

\section{Experimental design}

Experiment I: This experiment was designed to investigate the effect of cryodevices (MVAC and Cryotop) used for vitrification of bovine IVM oocytes on oocyte development rates after IVF. To serve as the solution control group, some IVM oocytes were exposed to equilibration medium, vitrification medium and warming solutions without cooling. Untreated oocytes served as the fresh control group. In vitrified groups, IVM oocytes were randomly vitrified by the MVAC, MVAC in $\mathrm{LN}_{2}$ or Cryotop method (MVAC, MVAC in $\mathrm{LN}_{2}$ and Cryotop groups, respectively) and then warmed before IVF. After IVF, all oocytes were cultured in vitro. Rates of development of the oocytes to the blastocyst stage and cell numbers of the obtained blastocysts were compared between all five groups.

Experiment II: The objective of this experiment was to compare the efficiencies of the cryodevices for the vitrification of IVP blastocysts. Grade 1 IVP expanded blastocysts (IETS quality code 1, stage code $7 ; \mathrm{n}=455$ ) were randomly divided into four groups; the expanded blastocysts were 1) exposed to vitrification and warming solutions (solution control group), 2) vitrified by the MVAC method (MVAC group), 3) vitrified by the MVAC in $\mathrm{LN}_{2}$ method (MVAC in $\mathrm{LN}_{2}$ group) or 4) vitrified by the Cryotop method (Cryotop group). Blastocyst survival after vitrification-warming was assessed by their hatching ability during $72 \mathrm{~h}$ of additional IVC.

\section{Statistical analysis}

The percentages of IVM-IVF oocytes that developed to the blastocyst stage and survival rates of IVP blastocysts after vitrificationwarming were arcsine transformed. Cell numbers of the embryos were expressed as untransformed means \pm standard error of the mean (SEM). Data were analyzed by analysis of variance (ANOVA). Differences were considered to be significant when $\mathrm{P}<0.05$.

\section{Results}

\section{Experiment I}

The developmental rates of fresh and vitrified-warmed oocytes after IVF are shown in Table 1. Oocytes from all vitrification groups showed lower rates of cleavage and development to the blastocyst stage than those from the fresh and solution control groups $(\mathrm{P}<$ $0.05)$. Cleavage rates of the vitrified oocytes did not differ between the MVAC, MVAC in $\mathrm{LN}_{2}$ and Cryotop groups. The cleavage rates of oocytes in all vitrified groups were lower than those of oocytes in the fresh and solution control groups $(\mathrm{P}<0.05)$; however, there was no difference in these rates between the two control groups. Rates of oocyte development to the blastocyst stage did not differ between the MVAC, MVAC in $\mathrm{LN}_{2}$ and Cryotop groups on days 7, 
Table 1. In vitro development of fresh bovine IVM oocytes (fresh control), bovine IVM oocytes treated with vitrification solution (solution control) and bovine IVM oocytes vitrified using the MVAC or Cryotop device after IVF and in vitro culture for 9 days

\begin{tabular}{|c|c|c|c|c|c|c|c|}
\hline \multirow{3}{*}{ Treatment group } & \multirow{3}{*}{$\begin{array}{c}\text { No. of IVF } \\
\text { oocytes }\end{array}$} & \multicolumn{6}{|c|}{ Oocytes cleaved and developed into blastocysts (\%) } \\
\hline & & \multicolumn{2}{|c|}{ Cleaved (day $2 *$ ) } & \multicolumn{4}{|c|}{ Blastocyst (BL) } \\
\hline & & Total & $\geq 5$ Cells & Day 7 & Day 8 & Day 9 & Total BL \\
\hline Fresh control & 150 & $\begin{array}{c}134 \\
(89.3)^{\mathbf{a}}\end{array}$ & $\begin{array}{c}90 \\
(60.0)^{\mathbf{a}}\end{array}$ & $\begin{array}{c}48 \\
(32.0)^{\mathbf{a}}\end{array}$ & $\begin{array}{c}14 \\
(9.3)^{\mathrm{a}}\end{array}$ & $\begin{array}{c}3 \\
(2.0)^{\mathbf{a}}\end{array}$ & $\begin{array}{c}65 \\
(43.3)^{\mathrm{a}}\end{array}$ \\
\hline Solution control & 150 & $\begin{array}{c}131 \\
(87.3)^{\mathbf{a}}\end{array}$ & $\begin{array}{c}93 \\
(62.0)^{\mathbf{a}}\end{array}$ & $\begin{array}{c}43 \\
(28.7)^{\mathbf{a}}\end{array}$ & $\begin{array}{c}15 \\
(10.0)^{\mathbf{a}}\end{array}$ & $\begin{array}{c}5 \\
(3.3)^{\mathrm{a}}\end{array}$ & $\begin{array}{c}63 \\
(42.0)^{\mathbf{a}}\end{array}$ \\
\hline MVAC & 145 & $\begin{array}{c}77 \\
(53.1)^{\mathbf{b}}\end{array}$ & $\begin{array}{c}59 \\
(40.7)^{\mathbf{b}}\end{array}$ & $\begin{array}{c}26 \\
(17.9)^{\mathbf{b}}\end{array}$ & $\begin{array}{c}6 \\
(4.1)^{\mathbf{b}}\end{array}$ & $\begin{array}{c}1 \\
(0.7)^{\mathbf{b}}\end{array}$ & $\begin{array}{c}33 \\
(22.9)^{\mathbf{b}}\end{array}$ \\
\hline MVAC in $\mathrm{LN}_{2}$ & 145 & $\begin{array}{c}81 \\
(55.9)^{\mathbf{b}}\end{array}$ & $\begin{array}{c}60 \\
(41.4)^{\mathbf{b}}\end{array}$ & $\begin{array}{c}24 \\
(16.6)^{\mathbf{b}}\end{array}$ & $\begin{array}{c}4 \\
(2.8)^{\mathbf{b}}\end{array}$ & $\begin{array}{c}1 \\
(0.7)^{\mathbf{b}}\end{array}$ & $\begin{array}{c}29 \\
(20.0)^{\mathbf{b}}\end{array}$ \\
\hline Cryotop & 145 & $\begin{array}{c}82 \\
(56.6)^{\mathbf{b}}\end{array}$ & $\begin{array}{c}63 \\
(43.5)^{\mathbf{b}}\end{array}$ & $\begin{array}{c}30 \\
(20.7)^{\mathbf{b}}\end{array}$ & $\begin{array}{c}5 \\
(3.5)^{\mathbf{b}}\end{array}$ & $\begin{array}{c}2 \\
(1.4)^{\mathbf{b}}\end{array}$ & $\begin{array}{c}37 \\
(25.5)^{\mathbf{b}}\end{array}$ \\
\hline
\end{tabular}

Five replications were performed. ${ }^{\mathbf{a}, \mathbf{b}}$ Values within a single column that have different superscripts are significantly different at $\mathrm{P}<0.05$ using one-way ANOVA. * Day 0 was defined as the day IVF was performed. MVAC: IVM oocytes that were vitrified by inserting the MVAC device containing them into a precooled 0.25 -ml plastic straw. MVAC in $\mathrm{LN}_{2}$ : IVM oocytes that were vitrified by plunging the MVAC device containing them directly into $\mathrm{LN}_{2}$. Cryotop: IVM oocytes that were vitrified by the Cryotop method.

8 or 9 ; however, they were lower than those of the fresh and solution control groups $(\mathrm{P}<0.05)$.

As shown in Fig. 1, there were no significant differences between all five groups in the total number of nuclei in blastocysts obtained on day 9. Similarly, no significant difference was found in the numbers of ICM and TE cells between all groups.

\section{Experiment II}

Rates of development to the hatched blastocyst stage of vitrifiedwarmed expanded blastocysts after $24 \mathrm{~h}$ of IVC differed between the MVAC in $\mathrm{LN}_{2}$ and solution control groups (35.1\% and $62.4 \%$, respectively; $\mathrm{P}<0.05)$; however, there were no significant differences in these rates between the solution control, MVAC and Cryotop groups. The rates of hatched embryos at 48 and $72 \mathrm{~h}$ of culture did not differ between the Cryotop, MVAC and MVAC in $\mathrm{LN}_{2}$ groups; moreover, no difference was observed in the rates of hatched embryos between the vitrified and solution control groups (Table 2).

\section{Discussion}

In this study, it was demonstrated for the first time that both bovine IVM oocytes and IVP expanded blastocysts can be successfully cryopreserved by the MVAC device. The triangular MVAC sheet (1.0 $\mathrm{mm}$ wide, $60 \mathrm{~mm}$ long, and $0.2 \mathrm{~mm}$ thick) is made from stainless steel, which supports high rates of heat exchange. High survival and developmental rates of vitrified-warmed IVM oocytes (Experiment I) and IVP embryos at the expanded blastocyst stage (Experiment II) were also achieved by the MVAC device as a result of rapid heat exchange and high cooling and warming rates.

Although Cryotop vitrification has been reported to be a highly efficient method for cryopreservation of bovine oocytes $[9,10]$ and embryos [35], the 0.4-mm-wide and 20-mm-long sheet allows for the placement of oocytes and embryos in less than $1 \mu 1$ of vitrification solution [36]. Thus, only 5-10 oocytes can be cryopreserved on

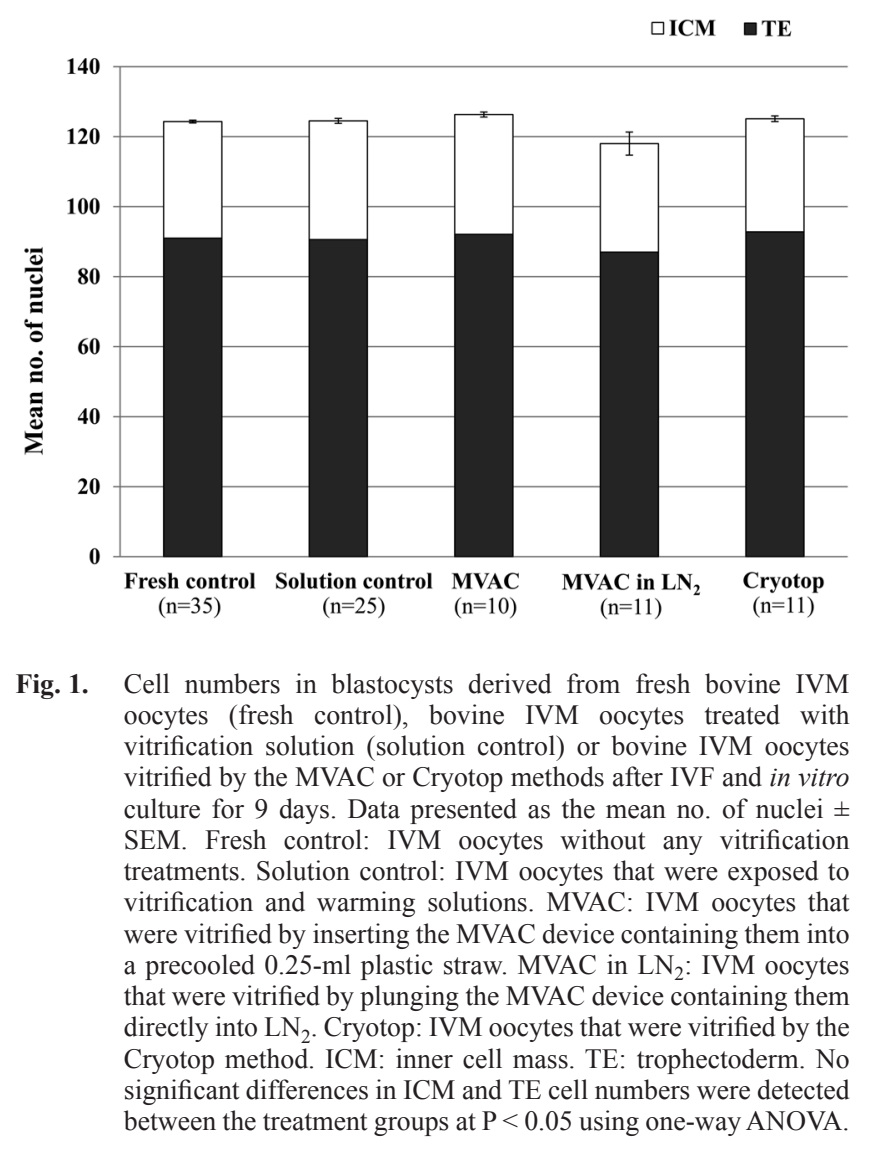

each Cryotop sheet [37]. In contrast, the longer sheet used in the MVAC method (60 vs. $20 \mathrm{~mm}$ ) can hold as many as 25 oocytes or blastocysts, according to our preliminary study (unpublished data).

Many viral and bacterial agents can survive in $\mathrm{LN}_{2}$ and be trans- 
Table 2. Development to the hatched blastocyst stage of in vitro-produced expanded blastocysts vitrified using the MVAC or Cryotop device, warmed and cultured in vitro for $72 \mathrm{~h}$

\begin{tabular}{|c|c|c|c|c|}
\hline \multirow{2}{*}{ Vitrification method } & \multirow{2}{*}{ No. of cryopreserved embryos } & \multicolumn{3}{|c|}{ No. of hatched embryos (\%) } \\
\hline & & $24 \mathrm{~h}$ & $48 \mathrm{~h}$ & $72 \mathrm{~h}$ \\
\hline \multirow[t]{2}{*}{ Solution control } & 117 & $73^{\mathrm{a}}$ & 94 & 109 \\
\hline & & $(62.4 \%)$ & $(80.3 \%)$ & $(93.2 \%)$ \\
\hline \multirow[t]{2}{*}{ MVAC } & 110 & $53^{\mathrm{ab}}$ & 88 & 102 \\
\hline & & $(48.2 \%)$ & $(80.0 \%)$ & $(92.7 \%)$ \\
\hline \multirow{2}{*}{ MVAC in $\mathrm{LN}_{2}$} & 114 & $40^{\mathrm{b}}$ & 82 & 104 \\
\hline & & $(35.1 \%)$ & $(71.9 \%)$ & $(91.2 \%)$ \\
\hline \multirow[t]{2}{*}{ Cryotop } & 114 & $61^{\mathrm{ab}}$ & 89 & 102 \\
\hline & & $(53.5 \%)$ & $(78.1 \%)$ & $(89.5 \%)$ \\
\hline
\end{tabular}

Six replications were performed. ${ }^{\mathrm{a}, \mathrm{b}}$ Values within a single column that have different superscripts are significantly different at $\mathrm{P}<0.05$ using one-way ANOVA. Solution control: IVP expanded blastocysts that were exposed to vitrification and warming solutions. MVAC: IVP expanded blastocysts that were vitrified by inserting the MVAC device containing them into a precooled 0.25 -ml plastic straw. MVAC in $\mathrm{LN}_{2}$ : IVP expanded blastocysts that were vitrified by plunging the MVAC device containing them directly into $\mathrm{LN}_{2}$. Cryotop: IVP expanded blastocysts that were vitrified by the Cryotop method. No significant difference in development to the hatched blastocyst stage was detected between the treatment groups at $\mathrm{P}<0.05$ using one-way ANOVA.

mitted into cryopreserved and banked embryos [38, 39]. Potential sources of contamination during freezing are the cryopreserved samples and $\mathrm{LN}_{2}$ themselves [40]. For example, when an infected embryo is stored in $\mathrm{LN}_{2}$, cross-contamination between it and $\mathrm{LN}_{2}$ may occur. Also, as water evaporates, it cools and freezes above the $\mathrm{LN}_{2}$ tank, forming small ice crystals with a high electrostatic charge. These ice crystals can capture airborne microorganisms, which in turn, fall into the tank [41, 42]. Pessoa et al. [43] reported that up to $84.3 \%$ of farms and $100 \%$ of companies in Southern Brazil use $\mathrm{LN}_{2}$ contaminated with bacteria, fungi, or both. Therefore, an alternative method for cryopreservation that avoids exposing samples directly to $\mathrm{LN}_{2}$ is required. In this study, the MVAC method without $\mathrm{LN}_{2}$ contact was shown to be as effective as the MVAC in $\mathrm{LN}_{2}$ and Cryotop methods, in which samples had direct contact with $\mathrm{LN}_{2}$. Because the actual heat transfer in the MVAC device was not investigated in Experiment I (because of the closed carriers), the MVAC device was employed in two separate methods to determine which method provided greater heat exchange during cooling. The results suggest that the heat exchange and cooling rates associated with direct plunging of the device into $\mathrm{LN}_{2}$ (MVAC in $\mathrm{LN}_{2}$ ) and without direct contact between the device and $\mathrm{LN}_{2}$ (MVAC) did not differ significantly from each other. A previous report on porcine embryos produced in vivo also showed equal efficiency between the MVAC and Cryotop vitrification methods [29]. However, because the stainless steel sheet of the MVAC device is non transparent, loading a small volume of the vitrification solution $(<1 \mu \mathrm{l})$ requires a great amount of skill.

In this study, a toxicity test of the vitrification solution showed that treatment with CPAs did not affect the developmental competence of vitrified IVM oocytes. Similar results have been reported previously in bovine IVM oocytes [8, 9, 37].

We achieved relatively high rates of development of vitrifiedwarmed IVM oocytes to the blastocyst stage, ranging from $20 \%$ to $25.5 \%$ for all vitrification methods. In general, higher cooling rates are expected to be achieved by open system methods, such as the Cryotop and MVAC in $\mathrm{LN}_{2}$ methods, than by closed system methods, such as the MVAC method, because conductive heat transfer is very rapid in $\mathrm{LN}_{2}$ [44]. However, our results showed that vitrified-warmed IVM oocytes had similar levels of competence to development to the blastocyst stage in all vitrification groups $(\mathrm{P}<0.05)$. These results indicate that all of the cooling systems investigated in this study are equally effective for cryopreservation of bovine IVM oocytes. Moreover, for the MVAC device, the recovery rates after warming of both bovine IVM oocytes and IVP expanded blastocysts were nearly $100 \%$ and did not significantly differ from those of the standard Cryotop method. The recovery rates for the MVAC device in our study were higher than those measured in a previous study of vitrified mouse oocytes, in which the recovery rates were $62 \%$ in an open pulled straw (OPS) and $81 \%$ in a $0.25-\mathrm{ml}$ plastic straw [45]. Abdelhafez et al. [28] reported lower recovery rates in mouse embryos vitrified by the Cryotip method than we report here; their recovery rates were $85 \%$ for the cleavage stage and $75 \%$ for the blastocyst stage. In this study, the cleavage rates of vitrified-warmed bovine IVM oocytes after IVF did not differ significantly between the treatment groups, ranging from $53 \%$ to $56 \%$; these rates are higher than the cleavage rates previously reported by Vajta et al. [22] (47-50\%) using the OPS method. Similarly, Sripunya et al. [37] reported that the cleavage rate of vitrified-warmed bovine IVM oocytes was $41 \%$. Our findings suggest that bovine IVM oocytes vitrified by the MVAC method, avoiding direct contact between the samples and $\mathrm{LN}_{2}$, can be fertilized with an efficiency equal to that of oocytes vitrified by other standard methods that allow direct contact with $\mathrm{LN}_{2}$ (Cryotop and MVAC in $\mathrm{LN}_{2}$ ). Furthermore, we found similar blastocyst rates and qualities (as measured by the numbers of TE cells and ICM cells, as well as by the total numbers of nuclei in the blastocysts) between the MVAC, MVAC in $\mathrm{LN}_{2}$ and Cryotop groups.

The results of our comparison study of the effect of cryodevices on the survival of IVP expanded blastocysts after vitrification-warming in experiment II showed that there was no significant difference between the Cryotop, MVAC, MVAC in $\mathrm{LN}_{2}$, and solution control groups $(\mathrm{P}<0.05)$. However, the rate of hatched blastocysts after warming and $24 \mathrm{~h}$ of IVC was lower in the MVAC in $\mathrm{LN}_{2}$ group 
than in the solution control group. The reasons for this low rate of hatched blastocysts in the MVAC in $\mathrm{LN}_{2}$ group are not clear; however, it may be partially explained by the difficulty of controlling the vitrification solution volume $(<1 \mu 1)$ in the MVAC device. Indeed, a higher volume of vitrification solution, which acts as an insulator surrounding the blastocysts, has been reported to result in decreased cooling viscosity and heat transfer $[3,36]$. However, the blastocyst viability in our MVAC in $\mathrm{LN}_{2}$ group was only slightly lower; later, at 48 and $72 \mathrm{~h}$ after warming, there were no significant differences in the rates of hatched blastocysts between the groups. Although direct comparison between our results and results obtained by previous studies is impossible, our results showed higher survival rates for vitrified-warmed bovine blastocysts treated with the Cryotop method than those previously reported using the same Cryotop method: $75 \%$ [46], $81.9 \%$ [47] and $47.6 \%$ [48].

In conclusion, the results of this study demonstrate that the Cryotop and MVAC cooling systems are equally effective for vitrification of both bovine IVM oocytes and bovine IVP embryos at the expanded blastocyst stage, resulting in high survival and developmental rates. Thus, we suggest that the MVAC system is a new, useful method for vitrification of both bovine IVM oocytes and bovine IVP embryos. Our results also show that the modified MVAC device used in the MVAC method may address biosafety concerns by serving as a closed carrier system that prevents exposure to $\mathrm{LN}_{2}$. However, it is necessary for future studies to investigate live calf production from oocytes and embryos vitrified by the MVAC method.

\section{Acknowledgments}

The authors would like to thank all members of the Embryo Transfer Team of the National Livestock Breeding Center, Fukushima, Japan, for technical support and Dr C Laowtammathron for his helpful suggestions regarding the manuscript. This work was supported by the NRCT-JSPS 2010 Joint Research Program, Suranaree University of Technology (SUT) and the Higher Education Research Promotion and National Research University Project of Thailand, Office of the Higher Education Commission, Thailand. K Punyawai was supported by a scholarship from Thailand Graduate Institute of Science and Technology's scholarship program (TGIS-CPMO-22-19-54-008D), awarded through the National Science and Technology Development Agency, Thailand. K Srirattana was supported by SUT postgraduate research fellowships.

\section{References}

1. Rall WF, Fahy GM. Ice-free cryopreservation of mouse embryos at $-196{ }^{\circ} \mathrm{C}$ by vitrification. Nature 1985; 313: 573-575. [Medline] [CrossRef]

2. Hochi S, Terao T, Kamei M, Kato M, Hirabayashi M, Hirao M. Successful vitrification of pronuclear-stage rabbit zygotes by minimum volume cooling procedure. Theriogenology 2004; 61: 267-275. [Medline] [CrossRef]

3. Arav A, Yavin S, Zeron Y, Natan D, Dekel I, Gacitua H. New trends in gamete's cryopreservation. Mol Cell Endocrinol 2002; 187: 77-81. [Medline] [CrossRef]

4. Arav A, Shehu D, Mattioli M. Osmotic and cytotoxic study of vitrification of immature bovine oocytes. J Reprod Fertil 1993; 99: 353-358. [Medline] [CrossRef]

5. Pereira RM, Marques CC. Animal oocyte and embryo cryopreservation. Cell Tissue Bank 2008; 9: 267-277. [Medline] [CrossRef]

6. Arav A, Zeron Y, Leslie SB, Behboodi E, Anderson GB, Crowe JH. Phase transition temperature and chilling sensitivity of bovine oocytes. Cryobiology 1996; 33: 589-599.
[Medline] [CrossRef]

7. Rho GJ, Kim S, Yoo JG, Balasubramanian S, Lee HJ, Choe SY. Microtubulin configuration and mitochondrial distribution after ultra-rapid cooling of bovine oocytes. $\mathrm{Mol}$ Reprod Dev 2002; 63: 464-470. [Medline] [CrossRef]

8. Martino A, Songsasen N, Leibo SP. Development into blastocysts of bovine oocytes cryopreserved by ultra-rapid cooling. Biol Reprod 1996; 54: 1059-1069. [Medline] [CrossRef]

9. Dinnyés A, Dai Y, Jiang S, Yang X. High developmental rates of vitrified bovine oocytes following parthenogenetic activation, in vitro fertilization, and somatic cell nuclear transfer. Biol Reprod 2000; 63: 513-518. [Medline] [CrossRef]

10. Chian RC, Kuwayama M, Tan L, Tan J, Kato O, Nagai T. High survival rate of bovine oocytes matured in vitro following vitrification. J Reprod Dev 2004; 50: 685-696. [Medline] [CrossRef]

11. Chen SU, Lien YR, Chao KH, Ho HN, Yang YS, Lee TY. Effects of cryopreservation on meiotic spindles of oocytes and its dynamics after thawing: clinical implications in oocyte freezing - a review article. Mol Cell Endocrinol 2003; 202: 101-107. [Medline] [CrossRef]

12. Massip A, Van Der Zwalmen P, Scheffen B, Ectors F. Pregnancy following transfer of cattle embryos preserved by vitrification. Cryo Lett 1986; 7: 270-273

13. Lane M, Schoolcraft WB, Gardner DK. Vitrification of mouse and human blastocysts using a novel cryoloop container-less technique. Fertil Steril 1999; 72: 1073-1078. [Medline] [CrossRef]

14. Lane M, Gardner DK. Vitrification of mouse oocytes using a nylon loop. Mol Reprod Dev 2001; 58: 342-347. [Medline] [CrossRef]

15. Vanderzwalmen P, Bertin G, Debauche C, Standaart V, Schoysman E. "In vitro" survival of metaphase II oocytes (MII) and blastocysts after vitrification in a hemi-straw (HS) system. Fertil Steril 2000; 74(Suppl 1): S215-216. (abstract). [CrossRef]

16. Vajta G, Holm P, Greve T, Callesen H. Vitrification of porcine embryos using the Open Pulled Straw (OPS) method. Acta Vet Scand 1997; 38: 349-352. [Medline]

17. Hochi S, Fujimoto T, Braun J, Oguri N. Pregnancies following transfer of equine embryos cryopreserved by vitrification. Theriogenology 1994; 42: 483-488. [Medline] [CrossRef]

18. Hamawaki A, Kuwayama M, Hamano S. Minimum volume cooling method for bovine blastocyst vitrification. Theriogenology 1999; 51: 165. (abstract). [CrossRef]

19. Isachenko V, Soler C, Isachenko E, Perez-Sanchez F, Grishchenko V. Vitrification of immature porcine oocytes: effects of lipid droplets, temperature, cytoskeleton, and addition and removal of cryoprotectant. Cryo Lett 2001; 22: 157-162.

20. Esaki R, Ueda H, Kurome M, Hirakawa K, Tomii R, Yoshioka H, Ushijima H, Kuwayama M, Nagashima H. Cryopreservation of porcine embryos derived from in vitro-matured oocytes. Biol Reprod 2004; 71: 432-437. [Medline] [CrossRef]

21. Ushijima H, Yoshioka H, Esaki R, Takahashi K, Kuwayama M, Nakane T, Nagashima H. Improved survival of vitrified in vivo-derived porcine embryos. J Reprod Dev 2004; 50: 481-486. [Medline] [CrossRef]

22. Vajta G, Holm P, Kuwayama M, Booth PJ, Jacobsen H, Greve T, Callesen H. Open Pulled Straw (OPS) vitrification: a new way to reduce cryoinjuries of bovine ova and embryos. Mol Reprod Dev 1998; 51: 53-58. [Medline] [CrossRef]

23. Dhali A, Manik RS, Das SK, Singla SK, Palta P. Vitrification of buffalo (Bubalus bubalis) oocytes. Theriogenology 2000; 53: 1295-1303. [Medline] [CrossRef]

24. Hufana-Duran D, Pedro PB, Venturina HV, Hufana RD, Salazar AL, Duran PG, Cruz LC. Post-warming hatching and birth of live calves following transfer of in vitroderived vitrified water buffalo (Bubalus bubalis) embryos. Theriogenology 2004; 61: 1429-1439. [Medline] [CrossRef]

25. Gasparrini B, Attanasio L, De Rosa A, Monaco E, Di Palo R, Campanile G. Cryopreservation of in vitro matured buffalo (Bubalus bubalis) oocytes by minimum volumes vitrification methods. Anim Reprod Sci 2007; 98: 335-342. [Medline] [CrossRef]

26. Kuwayama M, Kato O. All-round vitrification method for human oocytes and embryos $J$ Assist Reprod Genet 2000; 17: 477. (abstract).

27. Katayama KP, Stehlik J, Kuwayama M, Kato O, Stehlik E. High survival rate of vitrified human oocytes results in clinical pregnancy. Fertil Steril 2003; 80: 223-224. [Medline] [CrossRef]

28. AbdelHafez F, Xu J, Goldberg J, Desai N. Vitrification in open and closed carriers at different cell stages: assessment of embryo survival, development, DNA integrity and stability during vapor phase storage for transport. BMC Biotechnol 2011; 11: 29. [Medline] [CrossRef]

29. Misumi K, Hirayama Y, Egawa S, Yamashita S, Hoshi H, Imai K. Successful production of piglets derived from expanded blastocysts vitrified using a micro volume air cooling method without direct exposure to liquid nitrogen. J Reprod Dev 2013; 59: 520-524. [Medline] [CrossRef]

30. Imai K, Tagawa M, Yoshioka H, Matoba S, Narita M, Inaba Y, Aikawa Y, Ohtake M, Kobayashi S. The efficiency of embryo production by ovum pick-up and in vitro fertilization in cattle. J Reprod Dev 2006; 52(Suppl): 19-29.

31. Brackett BG, Oliphant G. Capacitation of rabbit spermatozoa in vitro. Biol Reprod 1975; 
12: 260-274. [Medline] [CrossRef]

32. Rosenkrans CF Jr, Zeng GQ, MCNamara GT, Schoff PK, First NL. Development of bovine embryos in vitro as affected by energy substrates. Biol Reprod 1993; 49: 459-462. [Medline] [CrossRef]

33. Thouas GA, Korfiatis NA, French AJ, Jones GM, Trounson AO. Simplified technique for differential staining of inner cell mass and trophectoderm cells of mouse and bovine blastocysts. Reprod Biomed Online 2001; 3: 25-29. [Medline] [CrossRef]

34. Abramoff MD, Magelhaes PJ, Ram SJ. Image processing with imageJ. Biophotonics Int 2004; $11: 36-42$.

35. Laowtammathron C, Lorthongpanich C, Ketudat-Cairns M, Hochi S, Parnpai R. Factors affecting cryosurvival of nuclear-transferred bovine and swamp buffalo blastocysts: effects of hatching stage, linoleic acid-albumin in IVC medium and Ficoll supplementation to vitrification solution. Theriogenology 2005; 64: 1185-1196. [Medline] [CrossRef]

36. Kuwayama M. Highly efficient vitrification for cryopreservation of human oocytes and embryos: the Cryotop method. Theriogenology 2007; 67: 73-80. [Medline] [CrossRef]

37. Sripunya N, Somfai T, Inaba Y, Nagai T, Imai K, Parnpai R. A comparison of cryotop and solid surface vitrification methods for the cryopreservation of in vitro matured bovine oocytes. J Reprod Dev 2010; 56: 176-181. [Medline] [CrossRef]

38. Bielanski A, Bergeron H, Lau PCK, Devenish J. Microbial contamination of embryos and semen during long term banking in liquid nitrogen. Cryobiology 2003; 46: 146-152. [Medline] [CrossRef]

39. Bielanski A. Non-transmission of bacterial and viral microbes to embryos and semen stored in the vapour phase of liquid nitrogen in dry shippers. Cryobiology 2005; 50: 206-210. [Medline] [CrossRef]
40. Bielanski A. A review of the risk of contamination of semen and embryos during cryopreservation and measures to limit cross-contamination during banking to prevent disease transmission in ET practices. Theriogenology 2012; 77: 467-482. [Medline] [CrossRef]

41. Grout BWW, Morris GJ. Contaminated liquid nitrogen vapour as a risk factor in pathogen transfer. Theriogenology 2009; 71: 1079-1082. [Medline] [CrossRef]

42. Morris GJ. The origin, ultrastructure, and microbiology of the sediment accumulating in liquid nitrogen storage vessels. Cryobiology 2005; 50: 231-238. [Medline] [CrossRef]

43. Pessoa GA, Rubin MIB, Silva CAM, Da Rosa DC. Decontamination of naturally contaminated liquid nitrogen storage tanks. R Bras Zootec 2014; 43: 244-249. [CrossRef]

44. Liebermann J, Tucker MJ. Effect of carrier system on the yield of human oocytes and embryos as assessed by survival and developmental potential after vitrification. Reproduction 2002; 124: 483-489. [Medline] [CrossRef]

45. Chen SU, Lien YR, Chen HF, Chao KH, Ho HN, Yang YS. Open pulled straws for vitrification of mature mouse oocytes preserve patterns of meiotic spindles and chromosomes better than conventional straws. Hum Reprod 2000; 15: 2598-2603. [Medline] [CrossRef]

46. De Rosa A, Attanasio L, Boccia L, Vecchio D, Campanile G, Gasparrini B. Cryotop vitrification for in vitro produced bovine and buffalo (Bubalus bubalis) embryos at different stages of development. Ital J Anim Sci 2007; 6(Suppl 2): 747-750.

47. Min SH, Lee E, Son HH, Yeon JY, Koo DB. Forced collapse of the blastocoel enhances survival of cryotop vitrified bovine hatching/hatched blastocysts derived from in vitro fertilization and somatic cell nuclear transfer. Cryobiology 2013; 66: 195-199. [Medline] [CrossRef]

48. Morató R, Mogas T. New device for the vitrification and in-straw warming of in vitro produced bovine embryos. Cryobiology 2014; 68: 288-293. [Medline] [CrossRef] 